\title{
Long-term outcomes of adding alpha- glucosidase inhibitors in insulin-treated patients with type 2 diabetes
}

\author{
Fu-Shun Yen ${ }^{1} \mathbb{B}$, James Cheng-Chung Wei ${ }^{2,3,4}$, Mei-Chen Lin ${ }^{5,6}$, Chih-Cheng Hsu ${ }^{7,8,9^{*}}$ (D) and Chii-Min Hwu ${ }^{10,11^{*}}$ (D)
}

\begin{abstract}
Background: In insulin-treated patients with type 2 diabetes mellitus (T2DM), glycemic control is usually suboptimal.

Methods: This study compared the risks of mortality and cardiovascular events in insulin-treated patients adding or not adding alpha-glucosidase inhibitors (AGIs).

Results: This cohort study included data from the Taiwan National Health Insurance Research Database. In total, 17, 417 patients newly diagnosed as having T2DM and undergoing insulin therapy during 2000-2012 were enrolled. Overall incidence rates of all-cause mortality, hospitalized coronary artery disease (CAD), stroke, and heart failure were compared between $4165 \mathrm{AGl}$ users and 4165 matched nonusers. The incidence rates of all-cause mortality were 17.10 and 19.61 per 1000 person-years in AGI nonusers and users, respectively. Compared with nonusers, AGl users had a higher mortality risk [adjusted hazard ratio $(\mathrm{aHR})=1.21,95 \%$ confidence interval $(\mathrm{Cl})=1.05-1.40 ; p=$ 0.01]. Regarding AGI use, aHRs (95\% Cl) for cardiovascular death, non-cardiovascular death, hospitalized CAD, stroke, and heart failure were 1.20 (0.83-1.74), 1.27 (1.07-1.50), 1.12 (0.95-1.31), $0.98(0.85-1.14)$, and $1.03(0.87-1.22)$ respectively.
\end{abstract}

Conclusion: AGl use was associated with higher risks of all-cause mortality and non-cardiovascular death in insulintreated patients with T2DM. Therefore, adding AGIs in insulin-treated patients may not be appropriate.

Keywords: Insulin, Alpha-glucosidase inhibitors, All-cause mortality, Cardiovascular death, Coronary artery disease

\section{Background}

Hyperglycemia increases cardiovascular risks [1]; even when lower than the diabetic threshold, blood glucose levels remain a continuous risk factor for cardiovascular death [2]. After adjustments for major risk factors, type 2 diabetes mellitus (T2DM) is associated with considerably increased risks of premature cardiovascular and

\footnotetext{
*Correspondence: cch@nhri.edu.tw; chhwu@vghtpe.gov.tw

${ }^{7}$ Institute of Population Health Sciences, National Health Research Institutes, No.35, Keyan Rd., Zhunan Township, Miaoli 35053, Taiwan

${ }^{10}$ Faculty of Medicine, National Yang-Ming University School of Medicine, No. 201, Sec. 2 Shi-Pai Rd., Chung-Cheng Build. 11F Room 522, Taipei 112, Taiwan

Full list of author information is available at the end of the article
}

non-cardiovascular deaths [3]. Thus, in the current clinical scenario, maintaining blood glucose levels within the reference range and preventing diabetic complications are essential. However, T2DM is a progressive disease characterized by a slow, continuous decline in $\beta$-cell function [4]. The UK Prospective Diabetes Study (UKPDS) revealed that after 3 years, approximately $50 \%$ of the patients required multiple therapies to meet their glycemic target [5]. Moreover, administration of exogenous insulin injections is frequently required for adequately treat T2DM. Even with insulin therapy, approximately $70 \%$ of patients with T2DM do not reach their therapeutic goal [6]. Insulin-treated patients may

(c) The Author(s). 2021 Open Access This article is licensed under a Creative Commons Attribution 4.0 International License, which permits use, sharing, adaptation, distribution and reproduction in any medium or format, as long as you give appropriate credit to the original author(s) and the source, provide a link to the Creative Commons licence, and indicate if changes were made. The images or other third party material in this article are included in the article's Creative Commons licence, unless indicated otherwise in a credit line to the material. If material is not included in the article's Creative Commons licence and your intended use is not permitted by statutory regulation or exceeds the permitted use, you will need to obtain permission directly from the copyright holder. To view a copy of this licence, visit http://creativecommons.org/licenses/by/4.0/ The Creative Commons Public Domain Dedication waiver (http://creativecommons.org/publicdomain/zero/1.0/) applies to the data made available in this article, unless otherwise stated in a credit line to the data. 
have higher mortality risks than do non-insulin-treated patients [7]. Yki-Järvinen [8] reported that using insulin combination therapy instead of insulin monotherapy can improve glycemic control. However, objective data on the combined use of oral agents and insulin injections are scant, and there is no consensus regarding the optimal insulin combination therapy.

Alpha-glucosidase inhibitors (AGIs) can reversibly bind to the carbohydrate-binding region of alphaglucosidases and thereby compete with oligosaccharide binding and delay the cleavage of oligosaccharides to monosaccharides. AGIs can thus retard intestinal glucose absorption and blunt postprandial hyperglycemia [9]. The reduction of postprandial glucose levels can attenuate glucose toxicity and increase insulin sensitivity. The results from the acarbose arm of UKPDS revealed that over a 3-year treatment course, acarbose had a persistent hemoglobin A1c (HbA1c) level-reducing effect similar to that of other therapies [10]. AGIs can also reduce fasting blood glucose levels and postprandial glucose excursion without increasing body weight. AGIs could be ideal complementary drugs in insulin combination therapy. Additionally, rice is the staple food in Asian people, AGIs can retard the absorption of carbohydrate and play an important role in controlling blood sugar in this area.

The Acarbose Cardiovascular Evaluation (ACE) trial [11] - a randomized, controlled trial in patients with impaired glucose tolerance and coronary heart disease-reported that acarbose had a neutral effect on major cardiovascular event outcomes. However, several shortterm ( $<1$ year) randomized, controlled trials have demonstrated that acarbose can significantly reduce $\mathrm{HbA1c}$ and postprandial glucose levels in insulin-treated patients with T2DM $[12,13]$. Furthermore, no relevant long-term results have been reported; therefore, in the current nationwide retrospective cohort study, we evaluated the long-term outcomes of adding AGIs in insulintreated patients with T2DM.

\section{Methods}

\section{Data source}

National Health Insurance (NHI) is a mandatory, singlepayer insurance program, implemented in Taiwan in 1995, that enrolls approximately $99 \%$ of Taiwan's residents (approximately 23 million people) [14]. We retrieved data from the NHI Research Database (NHIRD), which contains beneficiaries' information, including outpatient and inpatient claims, drug prescriptions, and medical procedures. Longitudinal Health Insurance Database 2000 (LHID2000), an NHIRD dataset, contains all the original claims data of 1,000,000 beneficiaries, randomly sampled from the NHIRD beneficiaries in 2000. These data include beneficiaries' birthdate, sex, medical orders, procedures, and medical diagnoses [according to the International Classification of Diseases, Ninth Revision, Clinical Modification (ICD-9-CM)]. We collected patient information from the LHID2000. In the LHID2000, information that could be used to identify individuals or care providers is concealed before release to researchers. The Research Ethics Committee of China Medical University and Hospital approved our study (CMUH104-REC2-115) and waived the need for informed consent.

\section{Study population}

The overall observation period of this retrospective cohort study was 14 years (January 1, 2000, to December 31, 2013). We selected patients newly diagnosed as having T2DM (ICD-9-CM: 250.x) at the age of 30-100 years during 2000-2012. To ensure diagnostic accuracy, only patients with $\geq 2$ diagnoses of T2DM in the outpatient claims or $\geq 1$ discharge diagnosis of T2DM in the inpatient claims were considered eligible for inclusion. All patients received insulin treatment after T2DM diagnosis.

We excluded patients diagnosed as having type 1 diabetes mellitus (ICD-9-CM: 250.1x) and hepatic failure (ICD-9-CM: 570, 572.2, 572.4, and 572.8), those undergoing dialysis (ICD-9-CM: 39.95, V56.0, V56.8, and V45.1), those with severe hypoglycemia at emergency department visits or hospitalization (to preclude patients with previous hypoglycemia), those with missing basic information, and those who had used AGIs before insulin prescription.

\section{AGI exposure}

We identified patients who received prescriptions of AGIs (including acarbose and miglitol) after receiving insulin therapy. The index date was defined as the date of first AGI use. AGI nonusers, defined as patients who did not use AGIs during the entire observation period, were randomly assigned an index date after insulin therapy, within the follow-up period.

\section{Comorbidities and other demographic information}

The comorbidities included in this study were coronary artery disease (CAD; ICD-9-CM: 410-414), stroke (ICD9-CM: 430-438), peripheral arterial occlusive disease (ICD-9-CM: 440.2x, 443.9, 84.1x, 39.25, 39.29, 39.50, and 39.59), heart failure (ICD-9-CM: 428), and atrial fibrillation (ICD-9-CM: 427.3). To increase the validity of the comorbidity diagnoses in the administrative dataset, only patients with $\geq 2$ outpatient or $\geq 1$ inpatient claim for these comorbidities were included. We also used the Charlson comorbidity index to quantify other comorbidity profiles of the patients [15]; the adapted Diabetes Complications Severity Index (aDCSI) score [16] was used to evaluate diabetes severity. The Charlson 
comorbidity index and Diabetes Complications Severity Index scores were calculated according to the patient status 1 year before the index date. We considered the use of basal, premixed, and prandial insulin; antidiabetic drugs other than AGIs (including metformin, sulphonylureas, dipeptidyl peptidase-4 inhibitors, and thiazolidinediones) after the date of diagnosis of diabetes; antihypertensive drugs [such as angiotensin-converting enzyme inhibitors (ACEIs), angiotensin II receptor blockers (ARBs), beta-blockers, calcium-channel blockers, diuretics, and potassium-sparing diuretics]; statins; and aspirin.

\section{Main outcomes}

The primary outcome of this study was all-cause mortality. Mortality was defined by discharge from hospital with certified death (the discharge date was defined as the death date) or by termination of the NHI coverage after discharge from hospital due to critical illness (the end of NHI coverage was defined as the death date). The secondary outcomes of this study were CAD, stroke, and heart failure hospitalizations. These cardiovascular events were assessed from the CAD, stroke, or heart failure diagnoses at hospitalization. Diagnostic accuracy of using ICD-9-CM in NHIRD has been validated previously [17]. The observation period was from the index date to the date of withdrawal from NHI, the date the outcomes were first noted, or December 31, 2013 (the end of the study), whichever occurred first. The primary diagnosis at discharge from hospitalization within 3 months before death was assessed for possible identifiable causes of death [18]. Identifiable causes of cardiovascular death were appropriated from the draft definition provided by Hicks et al. [19]; the diagnoses not included in cardiovascular-related deaths were classified as non-cardiovascular deaths.

\section{Statistical analysis}

Propensity score-matching was adopted to minimize bias due to confounding variables and augment comparability between the two study groups [20]. Nearest-neighbor probability was measured using a multivariable logistic regression model with AGI receipt as a dependent variable to construct matched pairs, in which the proportion between 0.995 and 1.0 indicated a perfect analog. We performed 1:1 propensity score-matching for sex, age, Charlson comorbidity index, Diabetes Complications Severity Index score, and comorbidity as well as for use of antidiabetic drug, antihypertensive drug, statin, and aspirin, by using multiple logistic regression analysis. Demographic information was analyzed using the chisquare and Student $t$ tests for categorical and continuous variables, respectively. Cox proportional hazard model was applied to estimate hazard ratios (HRs) and their
95\% confidence intervals (CIs) for events related to AGI use. The Kaplan-Meier method was used to calculate cumulative incidence of mortality, and the log-rank test was used to compare the difference in mortality between AGI users and nonusers. To evaluate the dose effect, we analyzed the risk of all-cause mortality according to the cumulative defined daily dose (DDD) of AGI use (< $12.47,12.47-74.96$, or $>74.96 \mathrm{DDD} /$ year), relative to AGI nonuse. Here, defined daily dose, the assumed average maintenance dose per day for adults, for both acarbose and miglitol was $300 \mathrm{mg}$. We considered a twotailed $p$ of $<0.05$ to be significant. The SAS (version 9.4 for Windows; SAS Institute, Inc., Cary, NC, USA) was used for data analysis.

\section{Results}

In total, 17,417 patients newly diagnosed as having T2DM receiving insulin therapy during 2000-2012 were included (Fig. 1). After exclusion of ineligible patients, 7335 AGI users and 6683 nonusers remained (Table 1). Compared with AGI users, more AGI nonusers were male and elderly; moreover, the nonusers had shorter diabetes durations, higher Charlson comorbidity index scores, lower Diabetes Complications Severity Index scores, and lower CAD incidence rates and had undergone less intensive treatments. After 1:1 propensity score-matching, the aforementioned variables did not differ significantly between AGI users and nonusers. Finally, both the study (users) and control (nonusers) cohorts each included 4165 patients. Approximately 48.1\% of all patients were women. The mean (standard deviation) age of AGI users and non-users were 64.2 (13.1) and 64.3 (13.2) years; the mean follow-up time of AGI users and non-users were 5.38 (3.22) and 4.78 (3.13) years, respectively.

Moreover, in AGI users and nonusers, 405 and 351 deaths occurred, respectively (incidence rate $=19.61$ and 17.10 per 1000 person-years, respectively; adjusted HR $(\mathrm{aHR})=1.21,95 \% \mathrm{CI}=1.05-1.40 ; p=0.010$; Table 2). Figure 2 illustrates the cumulative incidence of all-cause mortality based on the Kaplan-Meier method results, revealing a higher mortality risk in AGI users than in nonusers (log-rank test, $p=0.0551$ ).

As presented in Table 2, the aHRs of $<12.47,12.47-$ 74.96, and $>74.96$ cumulative DDD/year of AGI for allcause mortality were $1.15,1.15$, and 1.41 , respectively, with the $p$ for trend $=0.002$. As presented in Table 3, the aHRs for cardiovascular death, non-cardiovascular death, hospitalized CAD, stroke, and heart failure in AGI users compared with nonusers were $1.20,1.27,1.12,0.98$, and 1.03 , respectively.

Factors that increased risk of all-cause mortality included Charlson comorbidity index score of 1 or $\geq 2$, stroke or heart failure history, and diuretics use. Male 
Participants in LHID 2000 database (1996-2013)

$(\mathrm{N}=1,000,000)$

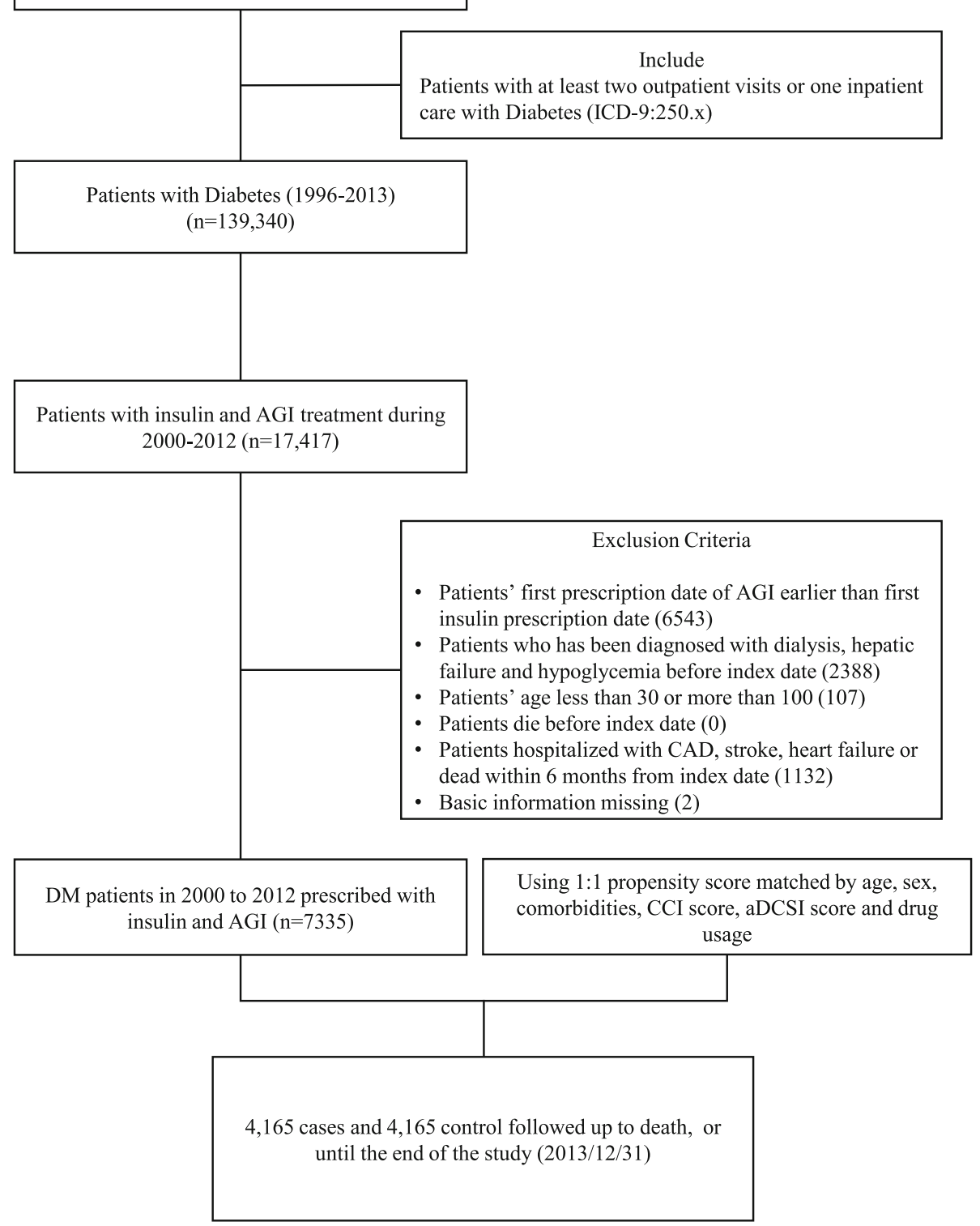

Fig. 1 Flow of patient selection and study design

patients as well as those aged 40-64 years or $\geq 65$ years were also at higher risk of all-cause mortality (Table 2). Dipeptidyl peptidase-4 inhibitor, thiazolidinedione, ACEI or ARB, beta-blocker, and statin use was associated with lower mortality risks.

\section{Discussion}

After propensity score-matching for multiple clinical variables, adding AGIs in insulin-treated patients were associated with higher risks of all-cause mortality compared with insulin-treated patients not adding AGIs. This mortality risk associated with AGI use displayed a dose-response trend. The increased risk of mortality was predominantly associated with non-cardiovascular death. Our study also demonstrated that adding AGIs in insulin-treated patients had no significant effect on the risks of hospitalized CAD, stroke, and heart failure as compared with patients not adding AGIs.

The STOP-NIDDM trial results revealed that acarbose use in patients with impaired glucose tolerance reduced cardiovascular disease risk [21]. However, the ACE trial indicated that in Chinese patients with impaired glucose tolerance and coronary heart disease, acarbose did not reduce the risk of major cardiovascular events [11]. A 
Table 1 Baseline characteristics of patients with T2DM receiving insulin with or without AGIS

\begin{tabular}{|c|c|c|c|c|c|c|c|c|}
\hline \multirow[t]{4}{*}{ Variable } & \multirow{2}{*}{\multicolumn{3}{|c|}{$\frac{\text { Before PSM }}{\text { DM with insulin treatment }}$}} & \multirow{4}{*}{$\begin{array}{l}P \text { - } \\
\text { value }\end{array}$} & \multirow{2}{*}{\multicolumn{3}{|c|}{$\frac{\text { After PSM }}{\text { DM with insulin treatment }}$}} & \multirow{4}{*}{$\begin{array}{l}P \text { - } \\
\text { value }\end{array}$} \\
\hline & & & & & & & & \\
\hline & \multirow{2}{*}{$\begin{array}{l}\text { Total } \\
N=14,018 \\
\mathrm{n}\end{array}$} & \multirow{2}{*}{$\begin{array}{l}\text { Non-AGI users } \\
(n=6683) \\
\text { n (\%) / Mean (SD) }\end{array}$} & \multirow{2}{*}{$\begin{array}{l}\text { AGI users } \\
(n=7335) \\
\mathrm{n}(\%) / \text { Mean (SD) }\end{array}$} & & \multirow{2}{*}{$\begin{array}{l}\text { Total } \\
N=8330 \\
\mathrm{n}\end{array}$} & \multirow{2}{*}{$\begin{array}{l}\text { Non-AGI users } \\
(n=4165) \\
\mathrm{n}(\%) / \text { Mean (SD) }\end{array}$} & \multirow{2}{*}{$\begin{array}{l}\text { AGI users } \\
(n=4165) \\
\mathrm{n}(\%) / \text { Mean (SD) }\end{array}$} & \\
\hline & & & & & & & & \\
\hline Gender & & & & 0.027 & & & & 0.324 \\
\hline Female & 6736 & 3146 (47.1) & 3590 (48.9) & & 4001 & 1978 (47.5) & 2023 (48.6) & \\
\hline Male & 7282 & 3537 (52.9) & 3745 (51.1) & & 4329 & $2187(52.5)$ & $2142(51.4)$ & \\
\hline Age, years & & & & $<0.001$ & & & & 0.864 \\
\hline$<40$ & 684 & $356(5.3)$ & $328(4.5)$ & & 345 & $177(4.3)$ & $168(4.0)$ & \\
\hline $40-64$ & 6463 & $2871(43.0)$ & $3592(49.0)$ & & 3814 & 1900 (45.6) & $1914(46.0)$ & \\
\hline$\geq 65$ & 6871 & $3456(51.7)$ & 3415 (46.6) & & 4171 & $2088(50.1)$ & $2083(50.0)$ & \\
\hline Mean (SD) & & $64.7(14.1)$ & $63.3(12.9)$ & $<0.001$ & & $64.3(13.2)$ & $64.2(13.1)$ & 0.833 \\
\hline \multicolumn{9}{|l|}{ Comorbidity } \\
\hline $\begin{array}{l}\text { Coronary artery } \\
\text { disease }\end{array}$ & 6334 & 2895 (43.3) & 3439 (46.9) & $<0.001$ & 3773 & $1887(45.3)$ & $1886(45.3)$ & 0.982 \\
\hline Stroke & 4609 & 2233 (33.4) & 2376 (32.4) & 0.199 & 2740 & $1380(33.1)$ & $1360(32.7)$ & 0.641 \\
\hline Heart failure & 2403 & 1178 (17.6) & $1225(16.7)$ & 0.146 & 1391 & $696(16.7)$ & $695(16.7)$ & 0.977 \\
\hline PAOD & 1429 & $629(9.4)$ & $800(10.9)$ & 0.004 & 892 & $438(10.5)$ & $454(10.9)$ & 0.571 \\
\hline Atrial fibrillation & 672 & $358(5.4)$ & $314(4.3)$ & 0.003 & 387 & $188(4.5)$ & 199 (4.8) & 0.567 \\
\hline CCl score & & & & $<0.001$ & & & & 0.811 \\
\hline 0 & 6281 & $2809(42)$ & $3472(47.3)$ & & 3702 & 1857 (44.6) & $1845(44.3)$ & \\
\hline 1 & 2954 & $1420(21.2)$ & 1534 (20.9) & & 1748 & $862(20.7)$ & $886(21.3)$ & \\
\hline$\geqq 2$ & 4783 & $2454(36.7)$ & 2329 (31.8) & & 2880 & $1446(34.7)$ & $1434(34.4)$ & \\
\hline aDCSI score & & & & $<0.001$ & & & & 0.867 \\
\hline 0 & 1903 & 1065 (15.9) & $838(11.4)$ & & 1079 & $534(12.8)$ & $545(13.1)$ & \\
\hline 1 & 1268 & $590(8.8)$ & $678(9.2)$ & & 725 & $358(8.6)$ & $367(8.8)$ & \\
\hline$\geqq 2$ & 10,847 & $5028(75.2)$ & $5819(79.3)$ & & 6526 & $3273(78.6)$ & $3253(78.1)$ & \\
\hline \multicolumn{9}{|l|}{ Medications } \\
\hline \multicolumn{9}{|l|}{ Insulin } \\
\hline Basal insulin & 7355 & $2772(41.5)$ & $4583(62.5)$ & $<0.001$ & 4535 & $2271(54.5)$ & $2264(54.4)$ & 0.878 \\
\hline Premixed insulin & 4226 & $1451(21.7)$ & 2775 (37.8) & $<0.001$ & 2535 & $1268(30.4)$ & $1267(30.4)$ & 0.981 \\
\hline Prandial insulin & 12,763 & $5966(89.3)$ & $6797(92.7)$ & $<0.001$ & 7602 & 3805 (91.4) & 3797 (91.2) & 0.756 \\
\hline \multicolumn{9}{|c|}{ Other antidiabetic drugs } \\
\hline Metformin & 11,807 & $4938(73.9)$ & 6869 (93.6) & $<0.001$ & 7620 & 3827 (91.9) & $3793(91.1)$ & 0.182 \\
\hline DPP-4 inhibitor & 4825 & $1403(21)$ & $3422(46.7)$ & $<0.001$ & 2736 & $1349(32.4)$ & $1387(33.3)$ & 0.375 \\
\hline Sulfonylurea & 11,536 & $4848(72.5)$ & $6688(91.2)$ & $<0.001$ & 7408 & 3719 (89.3) & 3689 (88.6) & 0.295 \\
\hline TZD & 5914 & $1684(25.2)$ & $4230(57.7)$ & $<0.001$ & 3307 & $1642(39.4)$ & $1665(40)$ & 0.607 \\
\hline \multicolumn{9}{|l|}{ Antihypertensive drugs } \\
\hline ACEI/ARB & 11,229 & $5060(75.7)$ & $6169(84.1)$ & $<0.001$ & 6788 & 3406 (81.8) & $3382(81.2)$ & 0.498 \\
\hline$\beta$-blocker & 7654 & $3462(51.8)$ & $4192(57.2)$ & $<0.001$ & 4392 & 2204 (52.9) & $2188(52.5)$ & 0.726 \\
\hline $\begin{array}{l}\text { Calcium-channel } \\
\text { blocker }\end{array}$ & 8078 & $3683(55.1)$ & $4395(59.9)$ & $<0.001$ & 4690 & $2353(56.5)$ & $2337(56.1)$ & 0.724 \\
\hline Diuretic & 8148 & $3731(55.8)$ & $4417(60.2)$ & $<0.001$ & 4666 & $2354(56.5)$ & $2312(55.5)$ & 0.354 \\
\hline $\begin{array}{l}\text { Potassium sparing } \\
\text { diuretic }\end{array}$ & 3091 & $1354(20.3)$ & $1737(23.7)$ & $<0.001$ & 1757 & $891(21.4)$ & $866(20.8)$ & 0.502 \\
\hline
\end{tabular}


Table 1 Baseline characteristics of patients with T2DM receiving insulin with or without AGls (Continued)

\begin{tabular}{|c|c|c|c|c|c|c|c|c|}
\hline \multirow[t]{4}{*}{ Variable } & \multirow{2}{*}{\multicolumn{3}{|c|}{$\frac{\text { Before PSM }}{\text { DM with insulin treatment }}$}} & \multirow{4}{*}{$\begin{array}{l}P \text { - } \\
\text { value }\end{array}$} & \multirow{2}{*}{\multicolumn{3}{|c|}{$\frac{\text { After PSM }}{\text { DM with insulin treatment }}$}} & \multirow{4}{*}{$\begin{array}{l}P \text { - } \\
\text { value }\end{array}$} \\
\hline & & & & & & & & \\
\hline & \multirow{2}{*}{$\begin{array}{l}\text { Total } \\
N=14,018 \\
\mathrm{n}\end{array}$} & \multirow{2}{*}{$\begin{array}{l}\text { Non-AGI users } \\
(n=6683) \\
\mathrm{n}(\%) / \text { Mean (SD) }\end{array}$} & \multirow{2}{*}{$\begin{array}{l}\text { AGI users } \\
(n=7335) \\
\mathrm{n}(\%) / \text { Mean (SD) }\end{array}$} & & \multirow{2}{*}{$\begin{array}{l}\text { Total } \\
N=8330 \\
\mathrm{n}\end{array}$} & \multirow{2}{*}{$\begin{array}{l}\text { Non-AGI users } \\
(n=4165) \\
\mathrm{n}(\%) / \text { Mean (SD) }\end{array}$} & \multirow{2}{*}{$\begin{array}{l}\text { AGI users } \\
(n=4165) \\
\mathrm{n}(\%) / \text { Mean (SD) }\end{array}$} & \\
\hline & & & & & & & & \\
\hline \multicolumn{9}{|l|}{ Other drugs } \\
\hline Statin & 8013 & 3134 (46.9) & $4879(66.5)$ & $<0.001$ & 4877 & $2443(58.7)$ & $2434(58.4)$ & 0.841 \\
\hline Aspirin & 8208 & $3751(56.1)$ & 4457 (60.8) & $<0.001$ & 4740 & $2389(57.4)$ & $2351(56.4)$ & 0.401 \\
\hline DM duration, year & & $12.1(4.5)$ & $12.8(4.5)$ & $<0.001$ & & $12.3(4.4)$ & $12.3(4.7)$ & 0.981 \\
\hline
\end{tabular}

SD Standard deviation, PAOD Peripheral arterial occlusive disease, CCI Charlson comorbidity index, aDCSI Adapted Diabetes Complications Severity Index, DPP-4 dipeptidyl peptidase-4, TZD Thiazolidinedione, ACEI Angiotensin-converting enzyme inhibitor, ARB Angiotensin II receptor blocker

meta-analysis of seven long-term randomized controlled trials found that compared with a placebo, acarbose could reduce myocardial infarction and cardiovascular event risks in patients with T2DM [22]. In their nationwide cohort study, Chang et al. demonstrated that metformin add-on AGI was associated with lower acute myocardial infarction risks compared with metformin add-on sulphonylurea [23]. Hsu et al. compared the use of acarbose as an add-on treatment to metformin with sulfonylurea, and reported low myocardial infarction and ischemic stroke hospitalization risks, but no effect on all-cause mortality [24]. AGIs can reduce HbA1c, postprandial glucose levels, and glucose excursion [25]. Subsequently, reduction in blood glucose levels can diminish the superoxide overproduction in the mitochondrial electron transport chain, which reduces oxidative stress [25]. Some studies have also determined that AGI use can restore endothelial function and reduce carotid intima-media thickening, low-grade inflammation, and cardiac interstitial fibrosis [25]. However, the Cochrane systematic review of acarbose use in patients with T2DM did not reveal any prognostic benefits on mortality or morbidity [26]. The long-term outcomes of AGI use remain inconclusive.

Some randomized controlled trials of adding acarbose in insulin-treated patients have revealed significant reductions in HbA1c and postprandial glucose levels [12, 13]; however, long-term outcomes have not been reported. The present study demonstrated that adding AGIs in insulin-treated patients have no significant effect on major cardiovascular events and cardiovascular death. This result is consistent with that of the aforementioned Cochrane systematic review [26] but differs from that of the MeRia study, Chang et al., and Hsu et al. This difference may be due to our patients having received insulin therapy; whereas in the other studies, patients were administered AGI monotherapy or metformin add-on dual therapy. Insulin-treated patients had longer T2DM duration with more complications, and
AGI administration may not have been sufficient to reverse the atherosclerotic events.

Our study indicated that AGI use in insulin-treated patients may increase mortality risk and that higher cumulative defined daily dose of AGI can increase the propensity of mortality compared with AGI nonuse. The mechanism of action of AGI in insulin-treated patients and the resulting mortality risk remains unknown. AGI use does not appear to have severe toxicity, except for flatulence and diarrhea, which are commonly noted among AGI users [9]. Poor appetite with flatulence and dehydration after diarrhea should be closely monitored in AGI users to prevent the related mortality.

Taken together, the following are our speculations regarding mortality risk and adding AGIs in insulintreated patients with T2DM. Although we balanced basal, prandial insulin, and oral antidiabetic drugs use between the study and control cohorts, combining AGI and insulin to treat hyperglycemia may not be as efficient for glycemic control as increasing insulin or combining insulin with other antidiabetic agents; the mortality risk reduction may also not be as efficient as other antidiabetic agents. Another possibility is that individuals who were on larger cumulative defined daily doses of AGI might have more suboptimal glycemic control with possible higher complication burden and mortality risk, and therefore required higher dose of AGI for achieving optimal glycemic control.

According to the draft of definition for cardiovascularrelated causes of death by Hicks et al. [19], which does not include cerebrovascular diseases, the proportion of cardiovascular and non-cardiovascular deaths in our study were 14.9 and $75.8 \%$, respectively. This result is consistent with the report of the national survey of mortality in Taiwan's patients with T2DM during 20052014 [27]. Thus, most of the deaths in our insulintreated patients with T2DM were non-cardiovascular.

Men, older patients, and patients with further comorbidities presented a higher mortality risk; these are high- 
Table 2 Mortality risk in patients with T2DM receiving insulin treatment

\begin{tabular}{|c|c|c|c|c|c|c|c|}
\hline \multirow[t]{2}{*}{ Characteristics } & \multirow{2}{*}{$\begin{array}{l}\text { Event no. } \\
(n=756)\end{array}$} & \multirow{2}{*}{$\begin{array}{l}\text { Person- } \\
\text { Year }\end{array}$} & \multirow[t]{2}{*}{ IR } & \multicolumn{2}{|l|}{ Crude } & \multicolumn{2}{|l|}{ Adjusted } \\
\hline & & & & HR $(95 \% \mathrm{Cl})$ & $p$ value & $\mathrm{HR}(95 \% \mathrm{Cl})$ & $P$ value \\
\hline \multicolumn{8}{|l|}{ AGl users } \\
\hline No & 351 & 20,529 & 17.10 & Ref. & & Ref. & \\
\hline Yes & 405 & 20,654 & 19.61 & $1.15(1.00-1.33)$ & 0.055 & $1.21(1.05-1.40)$ & 0.010 \\
\hline \multicolumn{8}{|c|}{ Cumulative defined daily doses of AGI therapy, per year } \\
\hline Non-users & 351 & 20,529 & 17.10 & Ref. & & Ref. & \\
\hline$\leqq 12.47$ & 153 & 7129 & 21.46 & $1.26(1.04-1.52)$ & 0.018 & $1.15(0.95-1.40)$ & 0.141 \\
\hline $12.47-74.96$ & 134 & 7539 & 17.77 & $1.04(0.85-1.26)$ & 0.730 & $1.15(0.94-1.40)$ & 0.180 \\
\hline$>74.96$ & 118 & 5986 & 17.92 & $1.17(0.95-1.44)$ & 0.141 & $1.41(1.14-1.74)$ & 0.001 \\
\hline$P$ for trend & & & & & 0.191 & & 0.002 \\
\hline \multicolumn{8}{|l|}{ Gender } \\
\hline Female & 318 & 20,740 & 15.33 & Ref. & & Ref. & \\
\hline Male & 438 & 20,442 & 21.43 & $1.41(1.22-1.63)$ & $<0.001$ & $1.57(1.35-1.82)$ & $<0.001$ \\
\hline \multicolumn{8}{|l|}{ Age, years } \\
\hline$<40$ & 6 & 2072 & 2.90 & Ref. & & Ref. & \\
\hline $40-64$ & 195 & 20,794 & 9.38 & $3.31(1.47-7.47)$ & 0.004 & $3.23(1.42-7.31)$ & 0.005 \\
\hline$\geq 65$ & 555 & 18,316 & 30.30 & $11.22(5.02-25.10)$ & $<0.001$ & $7.25(3.19-16.45)$ & $<0.001$ \\
\hline \multicolumn{8}{|l|}{ Comorbidity } \\
\hline Coronary artery disease & 414 & 18,013 & 22.98 & $1.57(1.36-1.81)$ & $<0.001$ & $0.86(0.73-1.01)$ & 0.074 \\
\hline Stroke & 376 & 12,076 & 31.13 & $2.44(2.12-2.82)$ & $<0.001$ & $1.3(1.10-1.52)$ & 0.002 \\
\hline Heart failure & 204 & 5645 & 36.14 & $2.40(2.04-2.82)$ & $<0.001$ & $1.31(1.09-1.58)$ & 0.004 \\
\hline PAOD & 89 & 3918 & 22.72 & $1.29(1.03-1.61)$ & 0.026 & $0.91(0.72-1.14)$ & 0.401 \\
\hline Atrial fibrillation & 67 & 1432 & 46.80 & $2.80(2.18-3.60)$ & $<0.001$ & $1.19(0.91-1.56)$ & 0.201 \\
\hline \multicolumn{8}{|l|}{ CCl score } \\
\hline 0 & 163 & 19,848 & 8.21 & Ref. & & Ref. & \\
\hline 1 & 154 & 8752 & 17.60 & $2.16(1.74-2.70)$ & $<0.001$ & $1.61(1.28-2.02)$ & $<0.001$ \\
\hline$\geqq 2$ & 439 & 12,583 & 34.89 & $4.36(3.64-5.22)$ & $<0.001$ & $2.41(1.97-2.96)$ & $<0.001$ \\
\hline \multicolumn{8}{|l|}{ aDCSI score } \\
\hline 0 & 63 & 6103 & 10.32 & Ref. & & Ref. & \\
\hline 1 & 44 & 4188 & 10.51 & $1.02(0.69-1.49)$ & 0.931 & $1.07(0.73-1.58)$ & 0.722 \\
\hline$\geqq 2$ & 649 & 30,892 & 21.01 & $2.08(1.61-2.70)$ & $<0.001$ & $0.92(0.69-1.23)$ & 0.594 \\
\hline \multicolumn{8}{|l|}{ Medications } \\
\hline \multicolumn{8}{|l|}{ Other antidiabetic drugs } \\
\hline Metformin & 671 & 37,840 & 17.73 & $0.69(0.55-0.87)$ & 0.002 & $0.79(0.60-1.03)$ & 0.081 \\
\hline DPP-4 inhibitor & 65 & 14,417 & 4.51 & $0.17(0.13-0.22)$ & $<0.001$ & $0.25(0.19-0.33)$ & $<0.001$ \\
\hline Sulfonylurea & 667 & 36,947 & 18.05 & $0.86(0.69-1.07)$ & 0.167 & $0.93(0.71-1.21)$ & 0.595 \\
\hline TZD & 207 & 17,940 & 11.54 & $0.48(0.41-0.57)$ & $<0.001$ & $0.64(0.54-0.76)$ & $<0.001$ \\
\hline \multicolumn{8}{|l|}{ Anti-hypertensive drugs } \\
\hline ACEI/ARB & 648 & 34,009 & 19.05 & $1.26(1.03-1.55)$ & 0.026 & $0.78(0.63-0.97)$ & 0.029 \\
\hline$\beta$-blocker & 469 & 23,231 & 20.19 & $1.25(1.08-1.45)$ & 0.003 & $0.83(0.70-0.99)$ & 0.041 \\
\hline Calcium-channel blocker & 501 & 24,484 & 20.46 & $1.33(1.14-1.54)$ & $<0.001$ & $1.05(0.87-1.26)$ & 0.613 \\
\hline Diuretic & 564 & 23,882 & 23.62 & $2.12(1.80-2.49)$ & $<0.001$ & $1.43(1.18-1.74)$ & $<0.001$ \\
\hline Potassium sparing diuretic & 295 & 8435 & 34.97 & $2.50(2.16-2.89)$ & $<0.001$ & $1.51(1.29-1.77)$ & $<0.001$ \\
\hline
\end{tabular}


Table 2 Mortality risk in patients with T2DM receiving insulin treatment (Continued)

\begin{tabular}{|c|c|c|c|c|c|c|c|}
\hline \multirow[t]{2}{*}{ Characteristics } & \multirow{2}{*}{$\begin{array}{l}\text { Event no. } \\
(n=756)\end{array}$} & \multirow{2}{*}{$\begin{array}{l}\text { Person- } \\
\text { Year }\end{array}$} & \multirow[t]{2}{*}{ IR } & \multicolumn{2}{|l|}{ Crude } & \multicolumn{2}{|l|}{ Adjusted } \\
\hline & & & & HR (95\% Cl) & $p$ value & HR (95\% Cl) & $P$ value \\
\hline \multicolumn{8}{|l|}{ Other drugs } \\
\hline Statin & 352 & 25,739 & 13.68 & $0.51(0.44-0.59)$ & $<0.001$ & $0.69(0.59-0.80)$ & $<0.001$ \\
\hline Aspirin & 523 & 24,954 & 20.96 & $1.44(1.24-1.68)$ & $<0.001$ & $1.15(0.95-1.39)$ & 0.140 \\
\hline
\end{tabular}

Adjusted HR was adjusted for sex, age, all comorbidities, and medications in Cox proportional hazards regression

SD Standard deviation, PAOD Peripheral arterial occlusive disease, CCI Charlson comorbidity index, aDCSI Adapted Diabetes Complications Severity Index, DPP-4

Dipeptidyl peptidase-4, TZD Thiazolidinedione, ACEI Angiotensin-converting enzyme inhibitor, ARB Angiotensin II receptor blocker

risk groups who need closely monitoring when considering insulin treatments. This study demonstrated that statin use was associated with a lower mortality risk than was statin nonuse-consistent with a previous meta-analysis of statin therapy [28]. Dipeptidyl peptidase-4 inhibitor use in insulin-treated patients was associated with higher survival rates-consistent with our previous results [29]. Thus, the addition of dipeptidyl peptidase- 4 inhibitors to insulin treatment may be a promising approach.

Our study revealed that ACEI and ARB use reduced mortality risk in insulin-treated patients; however, diuretic use for hypertensive treatment increased mortality risk. Most data suggested that adequate blood pressure control may be more critical than selecting particular agents for the management of hypertension [30]. As per the American Diabetes Association guidelines [30], the treatment of hypertension in patients with diabetes may include drugs that reduce the risk of cardiovascular events (such as ACEI, ARB or diuretics). However, the studies on the optimal drug choice for hypertensive treatment in patients with underlying insulin treatments are limited. Our study revealed that for treating hypertension in insulin-treated patients, ACEI or ARB might be more adequate than diuretics.

There are some limitations in this study. First, information on patients' smoking status, alcohol consumption, physical activity level, body weight, and height are not provided in the NHIRD; similarly, blood glucose, HbA1c, cholesterol levels and renal function status are not available in the database. Nevertheless, through the propensity scorematching of multiple critical variables by maximally controlling for the confounding factors has potentially increased the accuracy of our results. Second, when using the claims data for analysis, assessing patient adherence to the dosage of prescribed insulin or oral antidiabetic drugs is difficult. In addition, as insulin prescription in the NHI system is monitored as the number of insulin pens used for reimbursement purposes, we could not derive an accurate insulin dosage, which may influence the results of mortality and cardiovascular events. Third, we did not measure the risk of hypoglycemia in our study because we could not

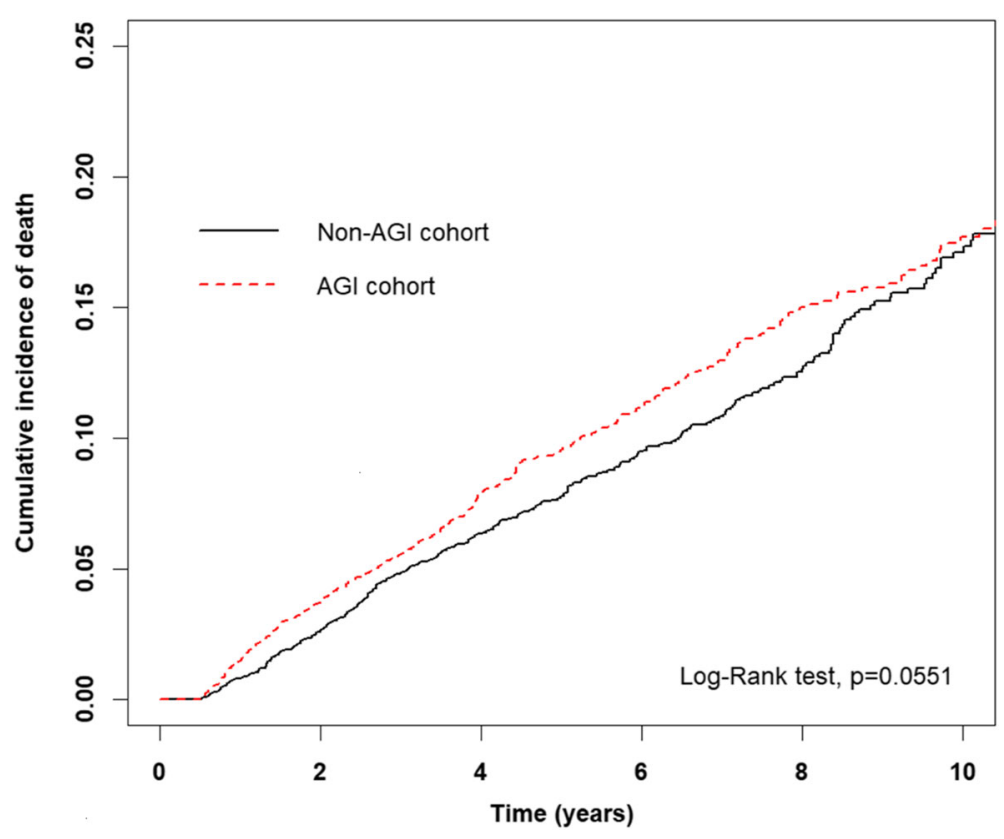

Fig. 2 Cumulative incidence of all-cause mortality in AGl users and nonusers 
Table 3 IRs and HRs for mortality, CAD, stroke, and HF hospitalization

\begin{tabular}{|c|c|c|c|c|c|c|c|c|}
\hline \multirow[t]{3}{*}{ Outcomes } & \multicolumn{6}{|l|}{ AGI } & \multicolumn{2}{|l|}{ Case vs. control } \\
\hline & \multicolumn{3}{|l|}{ No } & \multicolumn{3}{|l|}{ Yes } & \multirow{2}{*}{$\begin{array}{l}\text { Crude HR } \\
(95 \% \mathrm{Cl})\end{array}$} & \multirow{2}{*}{$\begin{array}{l}\text { Adjusted HR } \\
(95 \% \mathrm{Cl})\end{array}$} \\
\hline & Event & Person Years & IR & Event & Person Years & IR & & \\
\hline CV death & 54 & 20,529 & 2.63 & 59 & 20,654 & 2.86 & $1.10(0.76-1.60)$ & $1.20(0.83-1.74)$ \\
\hline Non-CV death & 259 & 20,529 & 12.62 & 314 & 20,654 & 15.20 & $1.21(1.02-1.42)^{*}$ & $1.27(1.07-1.50)^{*}$ \\
\hline Hospitalized CAD & 295 & 20,511 & 14.38 & 332 & 20,563 & 16.15 & $1.12(0.96-1.31)$ & $1.12(0.95-1.31)$ \\
\hline Hospitalized stroke & 358 & 20,332 & 17.61 & 354 & 20,533 & 17.24 & $0.98(0.85-1.13)$ & $0.98(0.85-1.14)$ \\
\hline Hospitalized HF & 281 & 20,042 & 14.02 & 288 & 20,081 & 14.34 & $1.02(0.87-1.21)$ & $1.03(0.87-1.22)$ \\
\hline
\end{tabular}

Adjusted HR was adjusted for sex, age, urbanization, and all comorbidities in Cox proportional hazards regression

$I R$ Incidence rate (per 1000 person-years), HR Hazard ratio, CI Confidence interval, CV Cardiovascular death, CAD Coronary artery disease, HF Heart failure ${ }^{*} p<0.05,{ }^{* *} p<0.01$

calculate the rates for hypoglycemia accurately from the database. Hypoglycemia incidence in outpatient claims might be underestimated because patients do not report their hypoglycemia to their physicians; inpatient records of hypoglycemia might also be underestimated because some hypoglycemic patients are cared for by family members without being admitted to hospitals or are referred to the emergency department without admission. Finally, because this was a retrospective cohort study, it contained some inevitable biases; a large scale randomized trial is needed to evaluate our results for therapeutic applications.

\section{Conclusions}

In summary, adding AGIs in insulin-treated patients might increase all-cause mortality risk as compared with no adding AGIs; and most of the increased death risk is from non-cardiovascular causes. Thus, future studies on addition of antidiabetic agents other than AGIs with insulin for superior glycemic control and long-term favorable prognosis are warranted.

\section{Abbreviations}

T2DM: Type 2 diabetes mellitus; AGl: Alpha-glucosidase inhibitor;

CAD: Coronary artery disease; DDD: Defined daily dose

\section{Acknowledgements}

This manuscript was edited by Wallace Academic Editing

\section{Authors' contributions}

FSY and CMH participated in the study design. JCW and MCL participated in the study coordination and data collection. MCL and $\mathrm{CCH}$ participated in the data analysis, all authors contributed in interpretation of the results and discussions. FSY and CMH participated in the manuscript writing. All named authors meet the International Committee of Medical Journal Editors (ICMJE) criteria for authorship for this manuscript, take responsibility for the integrity of the work, and have given approval for this paper to be published.

\section{Funding}

This study is supported in part by the Taiwan Ministry of Health and Welfare Clinical Trial Center (MOHW106-TDU-B-212-113004), China Medical University Hospital, Academia Sinica Taiwan Biobank Stroke Biosignature Project (BM10601010036), Taiwan Clinical Trial Consortium for Stroke (MOST 1062321-B-039-005), Taipei Veterans General Hospital (V105C-204). These funding agencies did not influence the study design, data collection and analysis, decision to publish, or preparation of the manuscript.
Availability of data and materials

Data are available from the National Health Insurance Research Database (NHIRD) published by Taiwan National Health Insurance (NHI) Bureau. The data utilized in this study cannot be made available in the paper, the supplemental files, or in a public repository due to the "Personal Information Protection Act" executed by Taiwan's government, starting from 2012. Requests for data can be sent as a formal proposal to the NHIRD (http:// nhird.nhri.org.tw) or by email to nhird@nhri.org.tw.

\section{Ethics approval and consent to participate}

The data utilized in this study cannot be made available in the paper, or in a public repository. Requests for raw data need to be permitted by the NHIRD Office (http://nhird.nhri.org.tw). The NHIRD office has permitted us to use the data for this study. In the LHID2000, information that could be used to identify individuals or care providers is concealed before release to researchers. The Research Ethics Committee of China Medical University and Hospital approved our study (CMUH104-REC2-115) and waived the need for informed consent.

\section{Consent for publication}

Not applicable.

\section{Competing interests}

The authors that they have no competing interests.

\section{Author details}

'Dr. Yen's Clinic, No. 15, Shanying Road, Gueishan District, Taoyuan 33354, Taiwan. ${ }^{2}$ Institute of Medicine, Chung Shan Medical University, No. 110, Sec. 1, Jianguo N. Rd., South District, Taichung City 40201, Taiwan. ${ }^{3}$ Department of Medicine, Chung Shan Medical University Hospital, No. 110, Sec. 1, Jianguo N. Rd., South District, Taichung City 40201, Taiwan. ${ }^{4}$ Graduate Institute of Integrated Medicine, China Medical University, No.91, Hsueh-Shih Road, Taichung 40402, Taiwan. ${ }^{5}$ Management Office for Health Data, China Medical University Hospital, 3F., No.373-2, Jianxing Road, Taichung 40459, Taiwan. ${ }^{6}$ College of Medicine, China Medical University, No. 110, Sec. 1, Jianguo N. Rd., South District, Taichung City 40201, Taiwan. ${ }^{7}$ Institute of Population Health Sciences, National Health Research Institutes, No.35, Keyan Rd., Zhunan Township, Miaoli 35053, Taiwan. ${ }^{8}$ Department of Health Services Administration, China Medical University, No.91, Hsueh-Shih Road, Taichung 40402, Taiwan. 'Department of Family Medicine, Min-Sheng General Hospital, 168 ChingKuo Road, Taoyuan 33044, Taiwan. ${ }^{10}$ Faculty of Medicine, National Yang-Ming University School of Medicine, No. 201, Sec. 2 Shi-Pai Rd., Chung-Cheng Build. $11 \mathrm{~F}$ Room 522, Taipei 112, Taiwan. ${ }^{11}$ Section of Endocrinology and Metabolism, Department of Medicine, Taipei Veterans General Hospital, No. 201, Sec. 2 Shi-Pai Rd., Chung-Cheng Build. 11F Room 522, Taipei 112, Taiwan.

Received: 23 October 2020 Accepted: 8 February 2021

Published online: 18 February 2021

\section{References}

1. Hanefeld M, Fischer S, Julius U, Schulze J, Schwanebeck U, Schmechel H, et al. Risk factors for myocardial infarction and death in newly detected 
NIDDM: the diabetes intervention study, 11-year follow-up. Diabetologia. 1996;39:1577-83.

2. Coutinho M, Gerstein HC, Wang Y, Yusuf S. The relationship between glucose and incident cardiovascular events: a meta regression analysis of published data from 20 studies of 95,783 individuals followed for 12.4 years. Diabetes Care. 1999:22:233-40.

3. Rao Kondapally Seshasai S, Kaptoge S, Thompson A, Di Angelantonio E, Gao P, Sarwar N. Diabetes mellitus, fasting glucose, and risk of cause-specific death. N Engl J Med. 2011;364:829-41.

4. United Kingdom Prospective Diabetes Study Group. United Kingdom prospective diabetes study 24: a 6-year, randomized, controlled trial comparing sulfonylurea, insulin, and metformin therapy in patients with newly diagnosed type 2 diabetes that could not be controlled with diet therapy. Ann Intern Med. 1998;128:165-75.

5. Turner RC, Cull CA, Frighi V, Holman RR. Glycemic control with diet, sulfonylurea, metformin, or insulin in patients with type 2 diabetes mellitus: progressive requirement for multiple therapies (UKPDS 49). JAMA. 1999;281: 2005-12.

6. Stark Casagrande S, Fradkin JE, Saydah SH, Rust KF, Cowie CC. The prevalence of meeting A1C, blood pressure, and LDL goals among people with diabetes, 1988-2010. Diabetes Care. 2013:36:2271-9.

7. Gamble JM, Simpson SH, Eurich DT, Majumdar SR, Johnson JA. Insulin use and increased risk of mortality in type 2 diabetes: a cohort study. Diabetes Obes Metab. 2010;12:47-53.

8. Yki-Järvinen H. Combination therapies with insulin in type 2 diabetes. Diabetes Care. 2001;24:758-67.

9. Lebovitz HE. Alpha-Glucosidase inhibitors. Endocrinol Metab Clin N Am. 1997;26:539-51.

10. Holman RR, Cull CA, Turner RC. A randomized double-blind trial of acarbose in type 2 diabetes shows improved glycemic control over 3 years (U.K. Prospective Diabetes Study 44). Diabetes Care. 1999;22:960-4.

11. Holman RR, Coleman RL, Chan JCN, Chiasson JL, Feng H, Ge J, et al. Effects of acarbose on cardiovascular and diabetes outcomes in patients with coronary heart disease and impaired glucose tolerance (ACE): a randomised, double-blind, placebo-controlled trial. Lancet Diabetes Endocrinol. 2017;5: 877-86

12. Coniff RF, Shapiro TB, Seaton $T B$, Hoogwerf BJ, Hunt JA. A double-blind placebo controlled trial evaluating the safety and efficacy of acarbose for the treatment of patients with insulin-requiring type 2 diabetes. Diabetes Care. 1995;18:928-32.

13. Hwu CM, Ho LT, Fuh MM, Siu SC, Sutanegara D, Piliang S, et al. Acarbose improves glycemic control in insulin-treated Asian type 2 diabetic patients: results from a multinational, placebo-controlled study. Diabetes Res Clin Pract. 2003;60:111-8.

14. Cheng TM. Taiwan's new national health insurance program: genesis and experience so far. Health Aff (Millwood). 2003;22:61-76.

15. Charlson ME, Pompei P, Ales KL, Mackenzie CR. A new method of classifying prognostic comorbidity in longitudinal studies: development and validation. J Chronic Dis. 1987:40:373-83.

16. Chang HY, Weiner JP, Richards TM, Bleich SN, Segal JB. Validating the adapted diabetes complications severity index in claims data. Am J Manag Care. 2012;18:721-6.

17. Sung SF, Hsieh CY, Lin HJ, Chen YW, Yang YHK, Li CY. Validation of algorithms to identify stroke risk factors in patients with acute ischemic stroke, transient ischemic attack, or intracerebral hemorrhage in an administrative claims database. Int J Cardiol. 2016;215:277-82.

18. Johansson LA, Westerling R. Comparing hospital discharge records with death certificates: can the differences be explained? J Epidemiol Community Health. 2002;56:301-8.

19. Hicks KA, James Hung HM, Mahaffey KW, et al. Standardized definitions for cardiovascular and stroke end point events in clinical trials. Draft definitions for CDISC. 2014. https://mdepinet.org/wp-content/uploads/S_1_6_Hicks.pdf. Accessed 19 Sept 2019.

20. D'Agostino RB Jr. Propensity score methods for bias reduction in the comparison of a treatment to a non-randomized control group. Stat Med. 1998;17:2265-81.

21. Chiasson JL, Josse RG, Gomis R, Hanefeld M, Karasik A, Laakso M, et al. Acarbose treatment and the risk of cardiovascular disease and hypertension in patients with impaired glucose tolerance: the STOP-NIDDM trial. JAMA. 2003:290:486-94.
22. Hanefeld M, Cagatay M, Petrowitsch T, Neuser D, Petzinna D, Rupp M. Acarbose reduces the risk for myocardial infarction in type 2 diabetic patients: meta-analysis of seven long-term studies. Eur Heart J. 2004;25:10-6.

23. Chang YC, Chuang LM, Lin JW, Chen ST, Lai MS, Chang CH. Cardiovascular risks associated with second-line oral antidiabetic agents added to metformin in patients with type 2 diabetes: a nationwide cohort study. Diabet Med. 2015;32:1460-9.

24. Hsu PF, Sung SH, Cheng HM, Shin SJ, Lin KD, Chong K, et al. Cardiovascular benefits of acarbose vs sulfonylureas in patients with type 2 diabetes treated with metformin. J Clin Endocrinol Metab. 2018;103:3611-9.

25. Standl E, Theodorakis MJ, Erbach M, Schnell O, Tuomilehto J. On the potential of acarbose to reduce cardiovascular disease. Cardiovasc Diabetol. 2014;13:81.

26. Van de Laar FA, Lucassen PL, Akkermans RP, Van de Lisdonk EH, Rutten GEHM, Van Weel C. Alpha-glucosidase inhibitors for type 2 diabetes mellitus. Cochrane Database Syst Rev. 2005;2:CD003639.

27. Li HY, Wu YL, Tu ST, Hwu CM, Liu JS, Chuang LM. Trends of mortality in diabetic patients in Taiwan: a nationwide survey in 2005-2014. J Formos Med Assoc. 2019;118:S83-9.

28. Collins R, Reith C, Emberson J, Armitage J, Baigent C, Blackwell L, et al. Interpretation of the evidence for the efficacy and safety of statin therapy. Lancet. 2016;388:2532-61.

29. Yen FS, Chiang JH, Hwu CM, Yen YS, Lin BJ, Wei JCC, et al. All-cause mortality of insulin plus dipeptidyl peptidase-4 inhibitors in persons with type 2 diabetes. BMC Endocr Disord. 2019;19:3.

30. de Boer IH, Bangalore $\mathrm{S}$, Benetos A, Davis AM, Michos ED, Muntner P, et al. Diabetes and hypertension: a position statement by the American diabetes association. Diabetes Care. 2017:40:1273-84.

\section{Publisher's Note}

Springer Nature remains neutral with regard to jurisdictional claims in published maps and institutional affiliations.

\section{Ready to submit your research? Choose BMC and benefit from:}

- fast, convenient online submission

- thorough peer review by experienced researchers in your field

- rapid publication on acceptance

- support for research data, including large and complex data types

- gold Open Access which fosters wider collaboration and increased citations

- maximum visibility for your research: over $100 \mathrm{M}$ website views per year

At $\mathrm{BMC}$, research is always in progress.

Learn more biomedcentral.com/submissions 